định làm cải thiện chất lượng cuộc sống nhiêu hớn phục hình kết hợp và cuối cùng là phục hình tháo lắp. Nghiên cứu của Amjid N và CS (2019) cho thấy phục hình cố định câu răng giải quyết được các vấn đề thẩm mỹ và chức năng ăn nhai hơn phục hình tháo lắp [1].

\section{KẾT LUẦN}

Kết quả nghiên cứu cho thây thấy có sự cải thiện chất lượng cuộc sống sau điêuu trị phục hình cố định hoặc/và phục hình tháo lắp bán phân 1 tháng. Sự khác biệt có ý nghĩa thống kê vê điểm trung bình OHIP-14 sau điều trị 1 tháng theo nhóm tuổi và loại phục hình $(p<0,05)$.

\section{TÀI LIẸU THAM KHẢO}

1. Amjid N., Muhammad A. C., Babar A., Mariya K., Siddiq Y., Iqbal H., Irtifaq A. N. (2019), "Oral health- related quality of life in prosthodontics patients of Sardar Begum Dental College Peshawar", JKCD, 9(2), pp. 28-33.

2. Katerina Z., Cena' D., Natasa L., Ivona K., Sanja N. (2020), "The Impact of oral health on quality of

life in partially edentulous patients before and after prosthodontics rehabilitions", Journal of Hygienic Engineering and Design, pp.89-94.

3. Montero J., et al. (2013), "Self-perceived changes in oral health-related quality of life after receiving different types of conventional prosthetic treatments: a cohort follow-up study", J Dent, 41(6), pp. 493-503.

4. Nguyen T. C., et al.(2010), "Oral health status of adults in Southern Vietnam - a cross-sectional epidemiological study", BMC Oral Health, 10: p. 2.

5. Organization World Health (1997), WHOQOL Measuring quality of life. Programme on Mental Health. Division of Mental Health and Prevention of Substance Abuse, 13(2): p. 13.

6. Reem H. W., Elfatih I. E. (2018), "Impact of Removable Partial Denture on Quality-of-life of Sudanese Adults in Khartoum State", The Journal of Contemporary Dental Practice,19(1), pp.102-108.

7. Slade Gary D. (1997), "Measuring Oral Health and Quality of Life", Department of Dental Ecology, School of Dentistry, University of North Carolina,

8. Swelem A. A., et al.(2014), "Oral health-related quality of life in partially edentulous patients treated with removable, fixed, fixed-removable, and implant-supported prostheses", Int J Prosthodont, 27(4): p. 338-47.

\title{
TỈ LỆ, ĐĂC ĐIỂM VÀ THÁI Độ XỬ TRÍ CHẤN THƯƠNG SỌ NÃO MÁU TỤ NGOÀI MÀNG CỨNG TẠI BỆNH VIÊ̂N ĐA KHOA TỈNH THÁI BÌNH
}

\section{TÓM TẮT}

Mục tiêu: Nhận xét tỉ lệ, nguyên nhân, đặc điểm máu tư ngoài màng cứng do chấn thương so não điều trị tại Bệnh viện Đa khoa tỉnh Thái Bình. Phương pháp: Mô tả cắt ngang 75 bệnh nhân máu tụ ngoài màng cứng do chấn thương sọ não điều trị tại Bệnh viên Đa khoa tỉnh Thái Bình trong khoảng thời gian từ tháng 2 tới tháng 9 năm 2020. Kết quả: Tỉ lệ máu tụ ngoài cứng $(14,0 \%)$ : 75/534 bệnh nhân chấn thương sọ não nhập viện điều trị trong khoảng thời gian 8 tháng. 75 bênh nhân gồm 64 nam $(85,3 \%) ; 11$ nữ $(14,7 \%)$; Tuổi trung bình: 34,2 \pm 21,2 tuổi; Độ tuổi lao động chiếm nhiêu nhất $47 / 75$ chiếm $(62,6 \%)$. Nguyên nhân do tai nạn giao thông chiếm cao nhất (68\%); Lâm sàng $74 / 75$ bênh nhân mức độ nhẹ $(98,7 \%)$; Cắt lớp vi tính: Vị trí máu tu vùng thái dương $(70,7 \%)$; vị trí trán $(36,0 \%)$; vùng đỉnh $(14,7 \%)$. Xử trí: điều trị nội $84,0 \%$; phẫu thuật lấy máu tụ 16,0\%. Kết quả ra viện tốt $98,7 \%$; xấu 1 bệnh nhân; không có tử vong. Kết luận: Tí lệ máu tụ ngoài

*Trường Đại học Y Dược Thái Bình Chiu trách nhiếm chính: Vũ Minh Hải Email: vuminhhai777@gmail.com Ngày nhận bài: 19.3.2021

Ngày phản biện khoa học: 14.5.2021

Ngày duyệt bài: 21.5.2021
Vũ Minh Hải*

màng cứng chiếm $(14,0 \%)$ trong tổng số bệnh nhân chấn thương sọ não. Nguyên nhân do tai nạn giao thông gặp nhiều nhất (68\%). Nam giới chiếm đa số $(85,3 \%)$. Mức độ lâm sàng nhẹ tương ứng với thể tích máu tụ nội sọ nhỏ, nên xử trí đa số là điêu trị nội khoa. so não.

Tứ khóa: Máu tụ ngoài màng cứng; chấn thương

\section{SUMMARY}

\section{RATE, CHARACTERISTICS AND ATTITUDE OF MANAGING TRAUMATIC BRAIN INJURY WITH EPIDURAL HEMATOMA AT \\ THAI BINH GENERAL HOSPITAL}

Objectives: To evaluate the rate, causes, and characteristics of epidural hematoma due to traumatic brain injury treated at Thai Binh General Hospital. Methods: Cross-sectional descriptive study in 75 patients with epidural hematoma due to traumatic brain injury treated at Thai Binh General Hospital between February and September 2020. Results: Percentage of hematoma (14.0\%): 75/534 traumatic brain injury patients hospitalized for a period of 8 months. 75 patients, including 64 males $(85.3 \%) ; 11$ females $(14.7 \%)$; Median age: $34.2 \pm 21.2$ years old; Working age accounted for the most 47/75 (62.6\%). Traffic accidents composed the highest $(68 \%)$ in causes; Clinically: 74/75 patients with minor level $(98.7 \%) ;$ CT scan: temporal epidural hematoma 
(70.7\%); frontal (36.0\%); parietal (14.7\%). Treatment: Medications: 84.0\%; Craniotomy \& Evacuation of Extradural Hematoma $16.0 \%$. Good discharge outcomes $98.7 \%$; bad 1 patient; no deaths. Conclusion: The rate of epidural hematoma accounted for $(14.0 \%)$ in the total number of traumatic brain injury patients. The most common cause was traffic accidents (68\%). Men made up the majority (85.3\%). The minor clinical severity corresponded to a small intracranial hematoma volume, so the majority of management is medications.

Keywords: Epidural, extradural hematoma; traumatic brain injury.

\section{I. ĐĂT VẤN ĐỀ}

Máu tụ ngoài màng cứng do chấn thương là một cấp cứu ngoại khoa thường gặp. Chẩn đoán máu tụ ngoài màng cứng tại tuyến tỉnh hiện tại đã dễ dàng hơn do được trang bị máy chụp cắt lớp vi tính. Vấn đề phẫu thuật cấp cứu những khối máu tụ ngoài màng cứng lớn, chèn ép não cũng đã thành thường quy và mang lại kết quả tốt cho bệnh nhân. Việc tuyên truyền phòng chống tai nạn thương tích đặc biệt là chấn thương sọ não đã có những hiệu quả nhất định. Tuy nhiên, để đánh giá những thay đổi về đặc điểm dịch tễ học lâm sàng của loại tổn thương này, giúp có bằng chứng khuyến cáo dự phòng và nâng cao chất lượng điêu trị nên chúng tôi tổng kêtt 75 trường hợp máu tụ ngoài màng cứng do chấn thương được điều trị tại Bệnh viện Đa khoa tỉnh Thái Bình.

\section{II. ĐỐI TƯỢNG VÀ PHƯƠNG PHÁP NGHIÊN CỨU}

2.1. Địa bàn nghiên cứu. Bệnh viện $Đ a$ khoa tỉnh Thái Bình.

2.2. Đối tượng nghiên cứu. 75 bệnh nhân máu tụ ngoài màng cứng điều trị tại khoa Phẫu thuật Thần kinh-Cột sống Bệnh viện Đa khoa tỉnh Thái Bình trong khoảng thời gian từ tháng 2 đến tháng 9 năm 2020.

\subsection{Phương pháp nghiên cứu}

Mô tả cắt ngang: tỉ lệ, nguyên nhân, lâm sàng, chẩn đoán hình ảnh và thái độ xử trí bệnh nhân máu tụ ngoài màng cứng.

\section{KẾT QUẢ NGHIÊN CỨU}

Bảng 3.1 Phân bố theo nhóm tuổi, giới

\begin{tabular}{|c|c|c|c|c|}
\hline Giới & \multicolumn{2}{|c|}{ Nam } & \multicolumn{2}{|c|}{ Nứ } \\
\cline { 2 - 5 } Nhóm tuối & n & \% & n & \% \\
\hline$\leq 18$ & 17 & 89,5 & 2 & 10,5 \\
\hline $19-29$ & 16 & 88,9 & 2 & 11,1 \\
\hline $30-39$ & 11 & 91,7 & 1 & 8,3 \\
\hline $40-49$ & 7 & 87,5 & 1 & 12,5 \\
\hline $50-59$ & 8 & 88,9 & 1 & 11,1 \\
\hline $60-69$ & 1 & 50,0 & 1 & 50,0 \\
\hline $70-79$ & 3 & 75,0 & 1 & 25,0 \\
\hline
\end{tabular}

\begin{tabular}{|c|c|c|c|c|}
\hline$\geq 80$ & 1 & 33,3 & 2 & 66,7 \\
\hline Tống & $\mathbf{6 4}$ & $\mathbf{8 5 , 3}$ & $\mathbf{1 1}$ & $\mathbf{1 4 , 7}$ \\
\hline \multicolumn{2}{|c|}{ Nhân xét: Tuối nhỏ nhất: $4 \cdot$ Tuối cao nhất: }
\end{tabular}

Nhân xét: Tuối nhỏ nhất: 4; Tuối cao nhất:

89; Tuổi trung bình: $34,21 \pm 21,22$

Giới: nam (85,3\%), nữ (14,7\%)

Bảng 3.2 Nguyên nhân chân thương

\begin{tabular}{|c|c|c|c|}
\hline $\begin{array}{c}\text { Nguyên nhân } \\
\text { chấn thương }\end{array}$ & $\mathbf{n}$ & $\begin{array}{c}\text { Tỷ lệ } \\
\mathbf{\%}\end{array}$ & $\begin{array}{c}\text { Tống } \\
\mathbf{\%}\end{array}$ \\
\hline Tai nạn giao thông & 51 & 68,0 & \multirow{2}{*}{98,7} \\
\hline Tai nạn lao động & 3 & 4,0 & \multirow{2}{*}{98,7} \\
\hline Tai nạn sinh hoạt & 20 & 26,7 & \\
\hline Bạo lực & 1 & 1,3 & 1,3 \\
\hline Tống & $\mathbf{7 5}$ & $\mathbf{1 0 0}$ & $\mathbf{1 0 0}$ \\
\hline
\end{tabular}

Nhận xét: Nguyên nhân do tai nạn giao thông chiếm cao nhất $68 \%$. Tiếp đó là tai nạn sịnh hoạt chiếm $(26,7 \%)$.

\section{Bảng 3.3 Các triệu chứng lâm sàng}

\begin{tabular}{|c|c|c|}
\hline Triệu chứng & n & Tỷ lệ \% \\
\hline Rối loạn tri giác & 4 & 5,3 \\
\hline Đauu đâu & 64 & 85,3 \\
\hline Nôn & 19 & 25,3 \\
\hline Co giật, động kinh & 1 & 1,3 \\
\hline Chảy máu mũi & 7 & 9,3 \\
\hline Chảy máu tai & 7 & 9,3 \\
\hline Bầm tím quanh mắt & 11 & 14,7 \\
\hline Tụ máu, sưng nề dưới & 25 & 33,3 \\
\hline da đâuu & 33 & 44,0 \\
\hline Vết thương rách da đầu & 33 & 25,3 \\
\hline Khác & 19 & \\
\hline
\end{tabular}

Nhận xét: Triệu chứng đau đầu 85,3\%; Vểt thương rách da đầu $44 \%$; Tụ máu, sưng nề dưới da đâu 33,3\%; nôn 25,3\%;

Bảng 3.4 Mức độ nặng theo tri giác

\begin{tabular}{|c|c|c|}
\hline GCS & $\mathbf{n}$ & Tỷ lệ $\%$ \\
\hline $13-15$ điếm & 74 & 98,7 \\
\hline $9-12$ điếm & 1 & 1,3 \\
\hline $3-8$ điếm & 0 & 0 \\
\hline
\end{tabular}

Nhận xét: $98,7 \%$ bệnh nhân vào viện trong tình trang nhe.

Bảng 3.5 Vị trí khôi máu tụ

\begin{tabular}{|c|c|c|}
\hline Vị trí khối máu tụ & $\mathbf{n}$ & Tỷ lệ \% \\
\hline Vùng trán & 27 & 36,0 \\
\hline Vùng thái dương & 53 & 70,7 \\
\hline Vùng đỉnh & 11 & 14,7 \\
\hline Vùng chấm & 7 & 9,3 \\
\hline
\end{tabular}

Nhận xét: Máu tụ vùng thái dương chiếm 70,7\%; Máu tụ vị trí trán 36,0\%; vùng đỉnh $14,7 \%$.

Bảng 3.6 Tổn thương phôi hợp với máu tụ ngoài màng cứng trên chụp CLVT

\begin{tabular}{|c|c|c|}
\hline Tốn thương & $\mathbf{n}$ & Tỷ lệ \% \\
\hline Vỡ xương sọ & 27 & 36,0 \\
\hline Phù não nặng & 1 & 1,3 \\
\hline $\begin{array}{c}\text { Máu tụ dưới màng cứng } \\
\text { cấp tính }\end{array}$ & 13 & 17,3 \\
\hline
\end{tabular}




\begin{tabular}{|c|c|c|}
\hline Máu tụ trong não & 2 & 2,7 \\
\hline Chảy máu màng mêm & 15 & 20,0 \\
\hline
\end{tabular}

Nhân xét: Vỡ xương so găp nhiều nhất $36 \%$; chảy máu màng mềm $20,0 \%$; máu tụ dưới màng cứng $17,3 \%$.

Bảng 3.7 Các tổn thương phôi hợp

\begin{tabular}{|c|c|c|}
\hline Tốn thương phối hợp & $\mathbf{n}$ & Tỷ lệ \% \\
\hline Vết thương rách da & 27 & 36,0 \\
\hline Vết thương bàn tay & 3 & 4,0 \\
\hline Chấn thương hàm mặt & 26 & 34,7 \\
\hline Chấn thương cột sống cố & 4 & 5,3 \\
\hline $\begin{array}{c}\text { Chấn thương cột sống } \\
\text { ngực thắt lưng }\end{array}$ & 2 & 2,7 \\
\hline Chấn thương ngực & 2 & 2,7 \\
\hline Chấn thương bụng & 1 & 1,3 \\
\hline Gãy xương & 10 & 13,3 \\
\hline
\end{tabular}

Nhân xét: Chấn thương hàm măt và vết thương rách da đâu chiếm tỉ lệ 34,7 và $36 \%$.

Bảng 3.8 Thái độ xử trí

\begin{tabular}{|c|c|c|}
\hline Thái độ xử trí & $\mathbf{n}$ & Tỷ lệ \% \\
\hline Điều trị nội khoa & 63 & 84,0 \\
\hline Phâuu thuất lấy máu tụ & 12 & 16,0 \\
\hline Tống số & $\mathbf{7 5}$ & $\mathbf{1 0 0}$ \\
\hline
\end{tabular}

Nhân xét: Tỉ lệ phấu thuật là 16,0\%; Đa số điêu trị nội khoa $84 \%$.

Bảng 3.9 Tình trạng tri giác khi ra viện

\begin{tabular}{|c|c|c|}
\hline Tình trạng tri giác & $\mathbf{n}$ & Tỷ lệ $\%$ \\
\hline Tốt (GCS 14-15đ) & 74 & 98,7 \\
\hline Khá (GCS 12-13đ) & 0 & 0 \\
\hline Trung bình (GCS 9-11đ) & 0 & 0 \\
\hline Kém (GCS 3-8đ) & 1 & 1,3 \\
\hline Tứ vong & 0 & 0 \\
\hline Tống & $\mathbf{7 5}$ & $\mathbf{1 0 0}$ \\
\hline
\end{tabular}

Nhân xét: Kết quả ra viện tốt 98,7\%; xấu 1 bệnh nhân; không có tử vong

\section{BÀN LUÂN}

4.1 Tỉ lệ máu tụ ngoài màng cứng. Nghiên cứu có 75/534 (14\%) bệnh nhân chấn thương sọ não máu tụ ngoài màng cứng nhập viện điều trị trong khoảng thời gian 8 tháng từ tháng 2 đến tháng 9 năm 2020. Theo Soon WC, Marcus $\mathrm{H}$, Wilson M (2016) tî lệ máu tụ ngoài màng cứng chiếm khoảng $2 \%$ các chấn thương sọ não [3]. Tuy nhiên, tỉ lệ trong nghiên cứu này lại tương đồng với nghiên cứu của Young $\mathrm{Ha}$ Jeong and et all (2016) tại Hàn Quốc: Trong số 2.698 bệnh nhân chấn thương sọ não được đăng ký trong Hê̂ thống Ngân hàng Dữ liệu Chấn thương Hàn Quốc từ tháng 9 năm 2010 đến tháng 3 năm 2014 (23 trung tâm chấn thương đã tham gia vào nghiên cứu một cách tự nguyện để thu thập dữ liệu).Trong số 2.698 trường hợp bệnh nhân chấn thương sọ não có 377 trường hợp máu tụ ngoài màng cứng, chiếm tỉ lệ

\section{$(13,9 \%)[4]$.}

4.2 Nguyên nhân chấn thương. Nghiên cứu này cho biết nguyên nhân do tai nạn giao thông chiếm tỉ lệ cao nhất $(68,0 \%)$, tiếp đó là tai nạn sịnh hoạt chiếm $(26,7 \%)$ chủ yếu gặp ở người cao tuổi. Theo Trần Đình Lợi (2009) trong 165 bệnh nhân chấn thương sọ não máu tụ ngoài màng cứng điều trị nội khoa tại bệnh viện Việt Đức thì nguyên nhân do tai nạn giao thông chiếm $(73,8 \%)$, do ngã là $(16,3 \%)$ [1].

4.3 Tuổi, giới. Nghiên cứu cho thấy tuổi trung bình là 34,21 $\pm 21,22$ tuổi. Tuổi nhỏ nhất là 4 tuổi, Tuổi cao nhất: 89 tuổi. Theo Trần Văn Lợi (2009) báo cáo 165 bệnh nhân thây lứa tuổi thường gặp nhất là 20 đến 30 tuổi, tuổi trung bình là $27,25 \pm 14,3$ [1].

Giới: nam $(85,3 \%)$, nữ $(14,7 \%)$, tỉ lệ nam/nữ là 5,8. Trần Văn Lợi (2009), Nam (78,26\%) nhiêu hơn nữ (21,73\%). Tỷ lệ nam/nữ là 4/1 [1].

4.4 Lâm sàng và chẩn đoán hình ảnh. Bệnh nhân của chúng tôi vào viện với triệu chứng đau đầu 85,3\%; Vết thương rách da đâu 44\%; Tụ máu, sưng nề dưới da đầu $33,3 \%$; nôn $25,3 \%$. Theo Trần Đình Lợi, triệu chứng chủ yếu trong nhóm nghiên cứu là đau đầu 147 (chiếm $89 \%$ ) và nôn là 59 trường hợp (chiếm 35,7\%) [1].

Tình trạng tri giác nhóm bệnh nhân của của tôi khi vào viê̂n (GCS: 13-15 điểm) chiếm 98,7\%. Trần Đình Lợi (2009) báo cáo bệnh nhân chấn thương sọ nã̃o máu tụ ngoài màng cứng không phẫu thuật có138/165 trường hợp $(83,6 \%)$ thang điểm 13 - 15 điểm, có 24/165 trường hợp $(14,5 \%)$ thang điểm từ $9-12$ điểm và chỉ $3 / 165$ trường hợp $(1,8 \%)$ thang điểm GCS $\leq 8$ điểm.

Chụp cắt lớp vi tính thây vị trí máu tụ ngoài màng cứng đa phần vùng thái dương chiếm (70,7\%); Máu tụ vị trí trán $36,0 \%$; vùng đỉnh $14,7 \%$. Các tổn thương phối hợp gồm võ xương sọ gặp nhiều nhất $36 \%$; chảy máu màng mềm 20,0\%; máu tụ dưới màng cứng 17,3\%. Vị trí máu tụ vùng thái dương của chúng tôi gặp nhiều hơn báo cáo của Trần Đình Lợi (2009) vùng thái dương là 67 trường hợp $(40,6 \%)$, còn vùng trán 51 trường hợp (30,9\%), hố sau có 5 trường hợp (3\%).

4.5 Thái độ xử trí. Đa số bệnh nhân chúng tôi điều trị nội khoa chiếm $84,0 \%$. Chỉ có 12 bênh nhân chiếm tỉ lệ $16,0 \%$ là xử trí phẫu thuật do khối máu tụ trên cắt lớp vi tính khi theo dỗi thây xấp xỉ 30 gram ở vùng thái dương, nguyên nhân do chảy máu từ đường vỡ xương tăng dần. Kết quả ra viện tốt $98,7 \%$; xâu 1 bệnh nhân do có tổn thương phối hợp chảy máu màng mềm, phù não nặng. Kết quả của Trần Đình Lợi (2009) cho biết bệnh nhân ra viện tỉnh, không liệt, đõ 
hoăc hết đau đầu GCS lúc ra viện 13 - 15 điểm, 149 trường hợp $(90,3 \%)$ không có di chứng. 15 trường hợp $(9,1 \%)$ ra viện có thang điểm là 9 12 điểm. Theo Young Ha Jeong và cộng sự (2016) tổng kết 285 bệnh nhân máu tụ ngoài màng cứng thì tỷ lệ có kết quả tốt là 87,7\% [4]. Theo nghiên cứu của Phạm Hoàng Thái và Đồng Văn Hệ (2012) thì kết quả phẩu thuật chấn thương so não đánh giá theo thang điểm GOSE thì số bệnh nhân có kết quả tốt chiếm 93,4\% [2].

Chúng tôi thây máu tụ ngoài màng cứng với tri giác GCS từ 13-15 điểm, máu tụ nhỏ thì đa số điều trị nội khoa cho kết quả tốt.

\section{KẾT LUÂN}

Tỉ lệ máu tụ ngoài màng cứng chiếm (14,0\%) trong tổng số bệnh nhân chấn thương sọ não. Nguyên nhân do tai nạn giao thông gặp nhiều nhất (68\%). Nam giới chiếm đa số (85,3\%). Mức độ lâm sàng nhẹ tương ứng với thể tích máu tụ nội sọ nhỏ, nên xử trí đa số là điều trị nội khoa.

\section{TÀI LIÊU THAM KHẢO}

1. Trân Đình Lợi (2009), "Đánh giá kết quả điều trị bảo tồn máu tụ ngoài màng cứng do chấn thương", Luận văn tốt nghiệp bác sĩ chuyên khoa cấp 2, trường Đai học Y Hà Nội, 2009.

2. Phạm Hoàng Thái, Đồng Vằn Hệ (2012), Đánh giá kết quả điều tri phẫu thuâtt chấn thương so não bằng thang điểm Glasgow Outcome Scale mở rộng tại Bệnh viện Việt Đức. Khóa luân tốt nghiệp bác sỹ Y khoa. Đại học Y Hà Nội, Hà Nội.

3. Soon wic, Marcus $H$, wilson M (2016). Traumatic acute extradural haematoma. Indications for surgery revisited. $\mathrm{Br}$ ] Neurosurg. 2016; 30: 233-234.

4. Young Ha Jeong, MD and et all (2016). Clinica Outcome of Acute Epidural Hematoma in Korea: Preliminary Report of 285 Cases Registered in the Korean. Trauma Data Bank System. Korean J Neurotrauma 2016;12(2):47 54.

\section{HIỆU QUẢ SỬ DƯNG SỮA HOÀN NGUYÊN BỔ SUNG VI CHẤT DINH DƯỡNG ĐỐI VỚI TÌNH TRANG NHÂN TRẮC TRẺ EM MẦM NON TẠI TỈNH YÊN BÁI, NĂM 2018}

\begin{abstract}
TÓM TẮT
Tăng cường vi chất dinh dưỡng (VCDD) vào thực phẩm là giải pháp quan trọng cải thiện tình trạng dinh dưỡng (TTDD) trẻ em. Nghiên cứu can thiệp cộng đồng ngẫu nhiên, có đối chứng đã được triển khai để đánh giá hiệu quả can thiệp sử dụng sữa hoàn nguyên bỗ sung 19 vi chất và khoáng chất (2 hộp/ngày, mỗi hộp180 ml) đối với tình trạng nhân trắc ở 666 trẻ từ 36 - 70 tháng tuổi tai trường mầm non trong thời gian 6 tháng. Kết quả cho thấy chỉ số cân nặng nhóm can thiệp tăng có ý nghĩa thống kê là $0,80 \mathrm{~kg}$ và $1,29 \mathrm{~kg}$ so với $0,59 \mathrm{~kg}$ và $1,07 \mathrm{~kg}$ ở nhóm chứng sau 3 và 6 tháng can thiệp $(p<0,001)$; các chỉ số chểnh lệch cân nặng $\left(T_{3}-T_{0}\right),\left(T_{6}-T_{0}\right)$ và chênh lệch $Z$-Score cẩn nặng theo tuổi và cân nặng theo chiều cao $\left(T_{3}-T_{0}\right)$, $\left(T_{6}-T_{0}\right)$ cải thiên có ý nghĩa thống kê $(p<0,001)$; Tuy nhiên chưa thẩy sự thay đối có ý nghĩa về tỷ lệ nguy cơ SDD và SDD nhe cân, thấp còi và gây còm giữa nhóm can thiêp so với nhóm chứng $(p>0,05)$. Có thể sử dụng sữa hoàn nguyên bổ sung vi chất như một thực phẩm bổ sung cho trẻ mẫu giáo để góp phần cải thiện TTDD. Tữ khóa: sữa hoàn nguyên, bổ sung vi chất, cân nặng, cải thiện dinh dưỡng, mầm non
\end{abstract}

${ }^{1}$ Viện Dinh dưỡng Quốc gia

Chịu trách nhiệm chính: Nguyễn Song Tú Email: nguyensongtu@dinhduong.org.vn Ngày nhâan bài: 22.3.2021

Ngày phản biên khoa hoc: 12.5.2021

Ngày duyệt bài: 24.5.2021
Nguyễn Song Tú ${ }^{1}$, Nguyễn Thị Lâm ${ }^{1}$, Hoàng Nguyễn Phương Linh', Nguyễn Thuý Anh ${ }^{1}$

\section{SUMMARY}

THE EFFICIENCY OF USING MICRONUTRIENTS FORTIFIED RECONSTITUTED MILK FOR ANTHROPOMETRIC STATUS OF PRESCHOOL CHILDREN IN YEN BAI PROVINCE, 2018

Micronutrient fortified food is an essential solution to improve the nutritional status of children. A randomized controlled study was conducted to evaluate the effectiveness of intervention using micronutrients fortified reconstituted milk with 19 micronutrients and minerals ( 2 boxes/180ml/day) for the anthropometric status of 666 children aged $36-$ 70 months at preschools. The results showed that the intervention group's weight was increased statistical significance of $0,80 \mathrm{~kg}$ and $1,29 \mathrm{~kg}$ compared to 0,59 $\mathrm{kg}$ and $1,07 \mathrm{~kg}$ in the control group after 3 and 6 months of intervention $(p<0.001)$. The difference of weight $\left(T_{3}-T_{0}\right),\left(T_{6}-T_{0}\right)$ and difference of weight for age z-score (WAZ) and weight for height z-score (WHZ) improved statistically $(\mathrm{p}<0.001)$; However, it had not found a significant change in the prevalence of the risk of underweight - stunting - wasting and underweight - stunting - wasting between the intervention group and the control group ( $p>0.05)$. Micronutrients fortified reconstituted milk can be used as a supplement for preschoolers to contribute to improving nutritional status.

Keywords: Constituted milk, micronutrient fortified, weight, nutritional improvement, preschool. 